\title{
Organização e controle do trabalho no capitalismo contemporâneo: a relevância de Braverman
}

\section{Work organization and control in contemporary capitalism: Braverman's relevance}

Fabiane Santana Previtali ${ }^{1}$

Cílson César Fagiani ${ }^{2}$

\section{Resumo}

Este artigo analisa a introdução de inovações técnicas e/ou organizacionais nos processos produtivos do capitalismo no século XXI. Entende-se que o conjunto de inovações representa, historicamente, formas de controle do trabalho no âmbito das relações de classe e reafirma as teses centrais de Braverman de sua obra "Trabalho e capital monopolista: a degradação do trabalho no século $X X$ ", publicado originalmente em 1974, sobre a tendência à desqualificação e à degradação do trabalho sob a lógica da acumulação do capital, contradizendo aquelas que defendem o fim da centralidade do trabalho. O estudo parte da revisão das teses de Braverman e da literatura pertinente ao tema.

Palavra-chave: Controle do Trabalho. Braverman. Processo de Trabalho. Qualificação.

\begin{abstract}
This article analyzes the introduction of technical and / or organizational innovations in the productive processes of capitalism in the $21^{\text {st }}$ century. It is understood that the set of innovations represents, historically, work control forms within class relations and it reaffirms Braverman's central theses from his work "Labor and monopoly capital: the degradation of work in the twentieth century", originally published in 1974, about the tendency to work deskilling and degradation under the rationale of capital accumulation, contradicting those that advocate for the end of work centrality. The study is based on the review of Braverman's theses and the literature pertinent the theme.
\end{abstract}

Keywords: Work Control. Braverman. Work Process. Qualification.

Artigo submetido em 27 de janeiro de 2014 e aceito para publicação em 25 de agosto de 2014.

DOI: http://dx.doi.org/10.1590/1679-395115088

1 Pós-doutorado na Universidade Nova de Lisboa. Instituto de História Contemporânea; Doutorado em Ciências Sociais pela Unicamp; Pesquisadora Fapemig, CNPq e Capes (set./2013 - ago./2014); Professora Associada II na Universidade Federal de Uberlândia; Coordenadora do Grupo de Pesquisa Trabalho, Educação e Sociedade (GPTES). Endereço: Av. João Naves de Ávila, 2121, Santa Mônica, CEP 38408-100, Uberlândia-MG, Brasil. E-mail: fabianesp@netsite.com.br

Doutorando em Educação pela Universidade Federal de Uberlândia; Doutorado-Sanduíche na Universidade Nova de Lisboa. Instituto de História Contemporânea; Pós-graduação em Educação. Apoio Fapemig e Capes (set./2013 - ago./2014). Endereço: Av. João Naves de Ávila, 2121, Santa Mônica, CEP 38408-100, Uberlândia-MG, Brasil. E-mail: cilsoncf@netsite.com.br 


\section{Introdução}

Harry Braverman publicou o livro "Trabalho e capital monopolista" em meados dos anos 1970, mais precisamente em 1974. A obra rapidamente se tornou leitura obrigatória no campo da esquerda e contribuiu sobremaneira para o que passou a ser chamado de teoria do processo de trabalho (MEIKSINS, 1994; YATES, 1999; SEWELL, 1998; 2005; THOMPSON, 2010). No livro, o autor defende a tese - polêmica - da tendência à desqualificação e degradação do trabalho no capitalismo. Passados quarenta anos do lançamento da obra, em meio às teses que defendem o fim da extrema separação entre concepção e execução do trabalho e do próprio trabalho enquanto criador do valor (PIORE e SABEL, 1984; HOFFMAN e KAPLINSK, 1988; WOMACK, JONES e ROOS, 1989), deve-se considerar a atualidade dos argumentos centrais de Braverman, fundamentalmente porque, à despeito das mudanças nos modelos de gestão, como o taylorismo/ fordismo, construído a partir dos anos 1930 (BIHR, 1998) e o desenvolvimento de novas formas organizacionais, como o toyotismo, este no âmbito da reestruturação produtiva relativa à crise que se instaura no capitalismo no final dos anos 1970 (HARVEY, 1992; 2011; ANTUNES, 2000; 2002; 2013), não há evidências de alterações substanciais na lógica da produção capitalista, a qual permanece sob a vigência da lei do valor e, portanto, sob a premissa do controle do trabalho.

Vale ressaltar que aqui não se está questionando a dinâmica das lutas de classes no local de trabalho e na estrutura sociopolítica capitalista, como defendem Burawoy (1978), Edwards (1979) ou Tomaney (1996). Ao contrário, é exatamente porque o trabalho cria mecanismos de resistência ao controle e à racionalização do capital que ele se vê obrigado a introduzir as mudanças para a extração da mais-valia.

Torna-se fundamental, portanto, o retorno a Braverman para entender como a essência do controle permanece sob um discurso ideológico que enfatiza a qualificação e a escolarização para a realização de um trabalho mais intelectual e menos manual, fundado na tecnologia informacional. Busca-se demonstrar como, no capitalismo do século XXI, a tendência à desqualificação e à degradação do trabalho não somente se mantém como se expande e se aprofunda, respaldada por políticas de flexibilização e de desregulamentação do trabalho.

Tomam-se como foco de discussão as teses centrais de Braverman (1981) presentes em "Trabalho e capital monopolista" e estudos desenvolvidos por pesquisadores brasileiros e estrangeiros acerca das mutações no mundo do trabalho a partir da década de 1990 e suas implicações na educação, particularmente no que tange à formação de novos modelos educacionais e pedagógicos e de formação de professores adequados às novas demandas do capitalismo na era da acumulação flexível. O artigo está estruturado de modo a apresentar, inicialmente, o processo de inovação no capitalismo sob a vigência da lei do valor, seguindo-se de uma discussão sobre as novas formas de controle do capital sob a ideologia da qualificação e do papel da educação na formação do novo trabalhador. Na última seção se apresenta a conclusão.

\section{Processo de Trabalho e Inovação Técnica no Capitalismo}

Segundo Marx (1988) e Braverman (1981), o valor não é uma condição natural da mercadoria, mas, sim, uma relação social que se materializa nelas. Apesar de assumir formas diferentes, o ato de trabalhar é sempre dispêndio produtivo de cérebro, músculos e nervos humanos, sendo, portanto, capacidade intrínseca ao homem que se realiza por sua ação sobre o meio. É trabalho concreto, dotado de habilidades e qualificações específicas.

Para os autores, a relação de produção e de troca no capitalismo abstrai o caráter concreto do trabalho. $\mathrm{O}$ valor é, então, esse acúmulo de trabalho humano abstraído de sua concretude e realizado em um tempo médio socialmente necessário, realizado em condições normais de produção, com grau médio de habilidade e intensidade do trabalho. Portanto, o valor das mercadorias é alterado de acordo com a produtividade do trabalho, que depende fundamentalmente da técnica e da habilidade para fazer algo. 
A introdução de inovações tecnológicas e organizacionais no processo de trabalho é uma constante no modo de produção capitalista. Marx (1988) foi um dos primeiros pensadores a tratar esses elementos como endógenos ao processo de acumulação desse modo de produção, analisando-os no contexto da dinâmica da luta entre as classes sociais do capitalismo. Cumpre ressaltar que a teoria de Marx (1988) sobre o processo de trabalho está intimamente relacionada à sua teoria das classes sociais, sendo o conceito de classe construído a partir das formas de apropriação do trabalho excedente que, por sua vez, relaciona-se com as formas de propriedade, ou seja, a propriedade ou não dos meios de produção.

No capitalismo, o processo de trabalho consiste em um processo de valorização do capital, sendo seu objetivo principal o aumento da produção da mais-valia. A questão que se coloca para o capital é a de como aumentar a produção da mais valia independentemente do prolongamento da jornada de trabalho. Esse processo torna-se possível por meio da redução do tempo de trabalho necessário - a parte do tempo que o trabalhador utiliza para si - e aumento do mais trabalho, que corresponde ao tempo de trabalho para o capitalista. Dessa forma, o capital aumenta a força produtiva do trabalho "mediante mudanças nos meios de trabalho ou nos métodos de trabalho ou em ambos" (Marx, 1988, p. 238) e o processo de valorização do capital passa a se estabelecer por meio da mais-valia relativa.

Portanto, o capital realiza a mais-valia relativa por meio de um processo de mudanças nos meios de produção e métodos de organização do trabalho por meio da aplicação da tecnologia, que, por sua vez, reduz o valor da mercadoria e da força de trabalho. Há um estímulo individual do capitalista para a redução do tempo de trabalho necessário que é o barateamento da mercadoria devido à concorrência dos demais capitalistas. A concorrência, assim, impele o capitalista a transformar as condições técnicas e organizacionais do processo de trabalho por meio da apropriação do saber dos trabalhadores (MARX, 1988).

Nesse sentido, o capitalista que introduz as inovações no processo produtivo tem a possibilidade de apropriar-se de maior parte da jornada de trabalho para o mais trabalho do que os demais capitalistas que ainda não o fizeram. Entretanto, essa mais-valia extra ${ }^{3}$, desaparece à medida que a inovação se generaliza na economia capitalista. Para Marx (1988), a empresa que consegue melhorar sua produtividade obtém uma maior mais-valia com o mesmo volume de capital. Esse fenômeno obriga os capitalistas, em sua luta competitiva, a aplicar na produção os mesmos conhecimentos da ciência e da técnica que seu concorrente a fim de aperfeiçoar o processo produtivo, organizando de modo mais eficiente a produção e o trabalho.

O aumento da força produtiva do trabalho estende-se pelos ramos da produção, por um lado, barateando a mercadoria e, por outro lado, reduzindo o valor da força de trabalho. Assim, a mais-valia extra desempenha importante papel no avanço do modo de produção capitalista e, ao mesmo tempo, no acirramento de suas contradições.

Há, dessa forma, um estímulo intrínseco ao modo de produção capitalista que faz com que o capitalista queira investir em novas técnicas de produção e organização do trabalho, alterando o conjunto das forças produtivas (MARX, 1988) ${ }^{4}$. Submetida à lógica dos interesses do capital, a ciência, transformada em tecnologia, converte-se em uma poderosa alavanca de exploração do trabalho e, portanto, de reprodução do capital em escala ampliada (MARX, 1988; BRAVERMAN, 1981).

Tem-se, assim, uma complexa e contraditória inter-relação entre ciência e valor, na medida em que seu potencial é limitado por sua determinação de classe. Nesse sentido, segundo Antunes (2000; 2002; 2013), as teses que argumentam sobre a preponderância da ciência e da técnica como forças produtivas nas sociedades

3

A mais-valia corresponde ao valor do sobre trabalho, ou seja, do trabalho não pago realizado pelo trabalhador para o capitalista e que constitui a base da repartição de rendimentos e da acumulação de capital. A obtenção da mais-valia extra está baseada na produtividade do trabalho em certa empresa em comparação com a produtividade média do trabalho na área da mesma atividade em empresas, encaradas em seu conjunto. Ver Marx (1988), Bihr (1998) e Harvey (1992).

${ }^{4}$ Para uma discussão mais aprofundada sobre a inovação técnica, ver Previtali (2009). 
contemporâneas são passíveis de críticas, pois, ao mesmo tempo que a ciência é liberada pelo capital para se expandir, ela é, em última instância, subordinada aos imperativos do processo de criação de valores de troca.

Dessa forma, o conhecimento social gerado pela ciência tem seu objetivo restringido pela lógica do capital, ao mesmo tempo que ocorre a apropriação desigual dos resultados e benefícios da ciência e da tecnologia, bem como do aumento da produtividade do trabalho social (ANTUNES, 2000; 2002; 2013). O autor destaca que a teoria do valor reconhece o papel crescente da ciência, mas ressalta que ela se encontra tolhida em seu desenvolvimento pela base material das relações entre capital e trabalho, à qual se encontra submetida, não podendo, sob o capital, tornar-se a principal força produtiva no lugar do trabalho.

Ademais, as teorias que postulam a substituição do trabalho como principal força produtiva desconsideram o fato de $2 / 3$ da força de trabalho estarem localizados nos países que ocupam uma posição economicamente periférica na divisão internacional do trabalho do Terceiro Mundo (HARVEY, 2011; ANTUNES, 2013). Como já lembrava Braverman (1981), a inovação fundamental não era encontrada na química, na eletrônica, na maquinaria automática, mas, antes, na transformação da própria ciência em capital, posto que os conhecimentos dos artesãos eram incorporados em máquinas construídas por engenheiros, a fim de obter a máxima eficiência possível do trabalho.

É nesse contexto que o controle exercido pela gerência torna-se, para Braverman (1981), o componente fundamental necessário às relações capitalistas de produção, na medida em que os trabalhadores não fornecem totalmente sua capacidade de trabalho, mas a retém por meio da responsabilidade de concepção e execução das tarefas. A gerência busca assegurar o controle, primeiro determinando as tarefas individuais e, depois, por meio da direção de todo o dia de trabalho para a certeza de que as tarefas serão cumpridas. Torna-se fundamental que a qualificação do trabalhador seja aquela requerida pelo capitalista, é indesejável, portanto, o conhecimento generalizado sobre o processo produtivo (BRAVERMAN, 1981).

Segundo Braverman (1981), o meio de impedir o controle do processo de trabalho pelos trabalhadores é a dissociação entre concepção e execução, isto é, entre trabalho intelectual e trabalho manual. O resultado dessa dissociação foi a desqualificação do trabalhador, dada a nova natureza que o trabalho adquire, reduzido a tarefas simplificadas e rotineiras, cada vez mais especializadas e sem conteúdo. Reforça-se, assim, para o autor, o perfil de um trabalhador desqualificado, que pode aprender em algumas semanas a produzir determinado bem, algo que antes demorava anos para acontecer.

Aos princípios da gerência científica de Taylor, Braverman (1981) associou a esteira rolante introduzida por Henry Ford na indústria automotiva. O local de trabalho é reorganizado, fixando o trabalhador em um ponto, o posto de trabalho, realizando os mesmos movimentos e utilizando as mesmas ferramentas. Os trabalhadores perdem não somente o controle e a capacidade de decisão sobre o processo de trabalho, eles também, passaram a ser colocados sob o domínio de uma estrutura administrativa fortemente hierarquizada (BRAVERMAN, 1981).

Portanto, sendo o trabalho o único gerador de valor, seu controle se faz necessário para a reprodução do capital. Segundo Braverman (1981), é por meio de inovações técnicas e/ou organizacionais que o capitalista apropria-se do conhecimento do trabalhador, expropriando o saber operário e garantindo a acumulação do capital. Na era da acumulação flexível do capitalismo contemporâneo, tais considerações de Braverman mostram-se extremamente pertinentes.

\section{As Novas Formas de Controle do Capital: Envolvimento e Participação}

Passados quarenta anos da publicação da primeira edição de "Trabalho e capital monopolista", é possível perceber o quanto as teses de Braverman (1981) continuam atuais. O contexto econômico, político, social e cultural do final do século XX e início do século XXI evidenciou as transformações societárias ocorridas em 
âmbito mundial, decorrentes da crise do regime de acumulação fordista ${ }^{5}$, estruturado com base no binômio taylorismo/fordismo que foi, segundo Antunes (2013), crescentemente alterado, mesclado e, alguns casos, substituído pelas formas produtivas flexibilizadas e desregulamentadas, das quais a chamada acumulação flexível e o modelo japonês ou toyotismo são exemplos.

Para Previtali (2009), essas transformações estão associadas a um processo de reestruturação das formas de organização e controle do trabalho ao longo das cadeias produtivas, por meio das quais o capital busca romper com a estrutura político-institucional de regulação, que proporcionou crescimento e relativa estabilidade durante o período taylorista/fordista. Por um lado, a reestruturação produtiva visa a responder à crise que se instala no regime taylorista/fordista de acumulação, a partir da segunda metade da década de 1970. Por outro lado, implica a construção de uma nova ordem de acumulação, porém, ainda circunscrita à lógica da reprodução do capital e fundada na dinâmica histórica das lutas de classes.

Com a crise que se instaura no regime de acumulação fordista a partir da segunda metade da década de 1970 , impõe-se às empresas a necessidade de encontrar uma força de trabalho mais complexa, mais heterogênea e mais multifuncional para ser explorada de forma mais intensa e sofisticada pelo capital (HARVEY, 1992; 2011; ANTUNES, 2000; 2002; 2013). Assim, o processo de reestruturação produtiva das empresas nada mais é que a reestruturação do capital, visando a assegurar sua expansão e acumulação.

A cada passo dado para a introdução da automação contemporânea, baseada na microeletrônica, há uma oportunidade para a destruição de formas de resistência ao controle do trabalho e à exploração (MILKMAN, 1997; BIHR, 1998; MILKMAN e LUCE, 2013). Cada vez mais as empresas beneficiam-se da desregulamentação neoliberal do trabalho para modificar suas relações com a classe trabalhadora, via intensificação dos processos de flexibilização envolvendo práticas como a terceirização e subcontratação, o trabalho temporário e o trabalho em grupo e impondo fortes derrotas ao movimento sindical que havia nascido sob as práticas tayloristas/fordistas. Para Harvey (2011, p. 16), "o neoliberalismo legitima práticas draconianas destinadas a restaurar e consolidar o poder da classe capitalista".

Nesse novo contexto, as mudanças tecnológicas e/ou organizacionais associadas ao toyotismo são apresentadas como as mais eficientes e racionais para o desempenho do processo produtivo, assim como a oportunidade de romper com os indesejáveis excessos da organização taylorista/fordista (PIORE e SABEL, 1984; WOMACK, JONES e ROOS, 1989). Para esses autores, cujas pesquisas foram realizadas na indústria automotiva, a difusão das novas tecnologias associada às novas práticas de gestão possibilitariam a recuperação da inteligência do trabalhador no local de trabalho, particularmente devido à introdução das células de produção e dos grupos de trabalho.

Para Sewell (1998; 2005), essa visão é superestimada e os autores que a defendem desconsideram a realidade do local de trabalho onde se evidencia que há uma limitada reintegração entre concepção e execução nos grupos de trabalho, havendo uma autonomia meramente nominal dos trabalhadores. A inovação, de fato, é que tais grupos passam a ser responsáveis pela racionalização e intensificação de seu próprio trabalho. As novas práticas gerenciais buscam a colaboração e o envolvimento dos trabalhadores de chão de fábrica por meio de pagamentos de prêmios individuais. Mas esse elemento, por si, não é uma novidade no campo do

5 O conceito de regime de acumulação diz respeito a um conjunto de práticas estabelecidas no chão de fábrica e nas relações sóciopolítico-culturais e educacionais no âmbito da dinâmica das relações de classe que se tornam predominantes em determinados momentos históricos, possibilitando o controle sobre o trabalho e a expansão e a acumulação do capital. Nesse sentido, são formas históricas predominantes de acumulação e expansão do capital no contexto da luta de classes, envolvendo controle e resistência no local de trabalho, bem como nas relações institucionais. O conceito tem sua origem na Teoria da Regulação, desenvolvida pelos autores da chamada Escola de Regulação Francesa nos anos 1960 e 1970, entre eles Aglietta, Boyer, Coriat, e Lipietz, para explicar o modo de produção capitalista, particularmente na fase de crescimento após a Segunda Guerra Mundial. $O$ regime de acumulação fordista proporcionou uma acumulação sustentada do capital pela instituição de uma negociação coletiva, envolvendo capital, trabalho e Estado, a qual procurou promover e assegurar, ao mesmo tempo, a acomodação dos trabalhadores ao processo de intensificação do trabalho e ao crescimento do mercado para o consumo com a intermediação de uma política macroeconômica, corporativa, que regulava produção, demanda, distribuição e consumo das mercadorias. Ver Aglietta (1979), Harvey (1992), Antunes (2002) e Carter, Danford, Howcroft et al. (2014). 
controle dos trabalhadores e da quebra de solidariedade de classe. A novidade consiste no desenvolvimento de elementos subjetivos que constrangem esses trabalhadores a participar da gestão de seu trabalho. Portanto, esses trabalhadores passam a ser cogestores da racionalização do processo produtivo.

Nesse sentido, segundo Antunes (2002, p. 52), "a subjetividade que emerge no local de trabalho é expressão de uma existência inautêntica e estranhada em relação ao que se produz e para quem se produz". Para o autor, o discurso do envolvimento e da participação do trabalhador, característico do toyotismo, leva em conta os objetivos da empresa, quase sempre fetichizados pelo discurso da parceria, da qualidade e da satisfação dos desejos do consumidor. Permanecem, portanto, as condições do trabalho alienado e estranhado.

Desde sua origem, da acumulação simples à grande indústria, o modo capitalista de produção empreende mudanças no processo produtivo de forma a subordinar o trabalho ao capital (PREVITALI, 2009). O que muda é a forma de implicação do elemento subjetivo na produção do capital, que, sob o taylorismo/fordismo, ainda era meramente formal, externo ao trabalhador, e com o toyotismo tende a ser real, com o capital buscando capturar a subjetividade operária de modo integral (ANTUNES e ALVES, 2004).

No taylorismo/fordismo, a realização das tarefas dependia fundamentalmente das aptidões físicas dos trabalhadores, sendo desprezada sua capacidade de pensar, uma vez que esta passa a ser função exclusiva da gerência. Segundo Braverman (1981, p. 112-113):

A consequência inexorável da separação de concepção e execução é que o processo de trabalho é agora dividido entre lugares distintos e distintos grupos de trabalhadores. Num local, são executados os processos físicos da produção; num outro estão concentrados o projeto, planejamento, cálculo e arquivo. A concepção prévia do projeto antes de posto em movimento; a visualização das atividades de cada trabalhador antes que tenham efetivamente começado; a definição de cada função; o modo de sua execução e o tempo que consumirá; o controle e a verificação do processo em curso uma vez começado; e a quota dos resultados após conclusão de cada fase do processo - todos esses aspectos da produção foram retirados do interior da oficina e transferidos para o escritório gerencial. Os processos físicos são agora executados mais ou menos cegamente, não apenas pelos trabalhadores que o executam, mas com frequência também por categorias mais baixas de empregados supervisores. As unidades de produção operam como a mão, vigiada, corrigida e controlada por um cérebro distante.

Já no toyotismo, o trabalhador é chamado a pensar para o capital. Para tanto, a gerência implementa um conjunto de estratégias de envolvimento e participação dos trabalhadores que vão desde a denominação do trabalhador como "colaborador" ou "associado", passando pela formação de grupos de resolução de problemas, com vistas à melhoria contínua, pela multifuncionalidade, pela aferição sistemática do desempenho e dos resultados obtidos, bem como pela quebra da resistência coletiva, do sindicalismo de classe e a concomitante constituição do sindicalismo de parceria capital/trabalho (ANTUNES e ALVES, 2004). Todo esse conjunto de medidas é construído com base em uma gestão fortemente individualizada e apoiada na aplicação de códigos de comportamento e atitudes que valorizam a participação e o empenho do trabalhador para com os objetivos e as metas da empresa (PREVITALI, 2009).

O sistema toyotista é fundado na organização da produção com base em uma resposta imediata às variações da demanda e que exige, portanto, uma organização flexível e integrada do processo de trabalho e dos trabalhadores. Considerado um elemento constituinte de uma nova fase de acumulação do capital, a acumulação flexível (HARVEY, 1992), esse sistema se apoia na flexibilidade dos processos de trabalho, dos mercados de trabalho, dos produtos e padrões de consumo; no surgimento de setores de produção inteiramente novos, novas maneiras de fornecimento de serviços financeiros, novos mercados e, sobretudo, em taxas altamente intensificadas de inovação comercial, tecnológica e organizacional (GOUNET, 1997; HARVEY, 1992; 2011; ANTUNES, 2000; 2002). 
Em um contexto no qual as palavras de ordem passam a ser a flexibilidade e a qualificação, as empresas observaram que muito do processo de inovação, particularmente as inovações incrementais no processo de trabalho, dependem da participação direta do trabalhador (PREVITALI, 2006). Segundo a autora, em pesquisa realizada no setor automotivo, quanto mais motivado e envolvido ele estiver com os objetivos da empresa, maiores serão as possibilidades de ocorrência de pequenas mudanças operacionais que impactarão de forma significativa a redução de custos, bem como a eficiência do processo produtivo e, dessa forma, a empresa estará mais bem adaptada às condições de concorrência no mercado.

Previtali (2006) observou que as empresas almejam o controle sobre uma capacidade de produção subjetiva, cognitiva, e sua aplicação no processo de inovação. As mudanças sugeridas pelos trabalhadores incluem adaptação de ferramental, agilidade de transporte de peças e de comunicação interna, apresentação do produto, uso mais racional de matérias-primas e de pessoal, visando à eficiência. Ao sugerir tais mudanças, o trabalhador acaba por colaborar com a gerencia administrativa, indicando-lhe onde o trabalho pode ser feito por menos pessoas e/ou em menor tempo, o que implica demissões e intensificação do trabalho para os que permanecem no emprego.

Sob a égide do trabalho multifuncional, combinam-se, muitas vezes no mesmo local de trabalho, trabalhadores estáveis e terceirizados, labor intelectual e esforço manual, cingidos pelo recorte de gênero como analisado por Pollert (1996) em uma indústria de chocolate na Inglaterra, por Nogueira (2006) no setor de telemarketing e por Previtali e Faria (2008) na indústria de cigarros, ambos últimos casos no Brasil. Previtali e Faria (2008) observaram que o trabalho intensivo em tecnologia era realizado por homens com maiores níveis de escolaridade e contratados pela empresa. Já o trabalho de empacotamento não automatizado, fundamentado no esforço repetitivo manual, era realizado por mulheres contratadas por empresa terceirizada.

O trabalho altamente qualificado e intelectualizado fundado na mais-valia relativa combina-se ainda, de modo complexo e contraditório, com o trabalho em condições de superexploração e de precarização, intensivo na extração da mais-valia absoluta, ao longo das mais diversas cadeias produtivas, de que é exemplo a agroindústria sucroalcooleira (SILVA, 1999; PREVITALI, MORAIS e FAGIANI, 2013). Em pesquisa sobre a expansão da agroindústria sucroalcooleira na região do Triângulo Mineiro a partir da década de 1990, os autores observaram que emprego de trabalho qualificado, especialmente relacionado à biotecnologia, coexiste com o emprego de trabalho manual migrante, em sua maioria nordestina, masculina e analfabeta, na colheita da cana-de-açúcar.

\section{Educação e Qualificação Profissional: A Construção do Novo Trabalhador}

Trabalho e educação são atividades especificamente humanas. Isso significa que apenas o ser humano trabalha e educa. Isso porque, no processo de surgimento do homem, constata-se a necessidade de ele produzir sua própria vida agindo sobre a natureza e ajustando-a às suas necessidades. A existência humana passa a ser produto de seu trabalho, seu agir sobre a natureza (FRIGOTTO, 2006; SAVIANI, 2007).

Para Saviani (2007), a essência humana não é dada ao homem, tampouco uma dádiva divina ou natural ou, ainda, algo que precede a existência do próprio homem. Na verdade, a essência humana é produzida pelos próprios homens em suas relações vivenciadas cotidiana e coletivamente, na construção de sua cultura e conhecimentos, através das gerações. Isso significa que o homem não nasce homem, ele forma-se homem à medida que o ato de trabalhar é, também, um ato de aprender e ensinar. A partir dessas considerações, o autor conclui que a origem da educação coincide com a origem do próprio homem.

[...] ele necessita aprender a ser homem, precisa aprender a produzir sua própria existência. Portanto, a produção do homem é, ao mesmo tempo, a formação do homem, isto é, um 
processo educativo. A origem da educação coincide, então, com a origem do homem mesmo (SAVIANI, 2007, p. 153).

Assim, a produção do homem é um processo educativo em que se apropria coletivamente dos meios de produção da existência, no qual aprende e ensina. O conhecimento é produzido no interior das relações sociais que se estabelecem entre os homens e destes com a natureza, portanto, nas relações sociais de produção historicamente constituídas.

Enquanto processo histórico, o saber é expropriado da classe trabalhadora e concentrado nas mãos dos detentores da propriedade ${ }^{6}$. Sob as relações capitalistas de produção, a forma que o capital encontrou para explorar ainda mais o trabalhador, ter controle sobre ele e aumentar a produtividade, foi a divisão técnica do trabalho, na qual se destaca a divisão entre trabalho manual e intelectual. Essa divisão do trabalho "é uma das condições de sobrevivência das sociedades capitalistas, uma vez que é determinada pela contradição fundamental entre capital e trabalho" (KUENZER, 2003, p. 14).

Nesse processo, somente uma pequena parcela da população tem acesso às condições para compreender a totalidade do processo de produção social. Esta é preparada para o mando e para o controle, perpetuando o ciclo de exploração.

Como explica Braverman (1981, p. 80),

Toda fase do processo do trabalho é divorciada, tão longe quanto possível do conhecimento e do preparo especial, e reduzida a simples trabalho. Nesse ínterim, as relativamente poucas pessoas para quem se reservam instrução e conhecimento são isentas tanto quando da obrigação de simples trabalho [...]. Esta poderia até ser chamada a lei geral da divisão do trabalho capitalista. Não é a única força atuando sobre a organização do trabalho, mas é certamente a mais poderosa e geral. Seus resultados, mais ou menos adiantados em cada indústria e ocupação, dão irrecusável testemunho de sua validade. Ela modela não apenas o trabalho, mas também populações, porque em longo prazo cria aquela massa de trabalho simples que é o aspecto principal das populações em países capitalistas desenvolvidos.

Assim, a educação não é alheia às transformações que se processam no modo de produção capitalista e tende a se ajustar às exigências demandadas por esta última, de modo que novos modelos educacionais e novas propostas pedagógicas são exigidos a acompanhar a evolução das inovações tecnológicas e de organização da produção na lógica da mercantilização do ensino.

A reforma da educação fundamenta-se nos relatórios e diagnósticos do Banco Mundial, do Fundo Monetário Internacional (FMI) e da Organização para a Cooperação e o Desenvolvimento Econômico (OCDE) e assenta-se em um discurso que vincula a necessidade de adequação dos países às transformações ocorridas nos setores produtivos e de serviço. Nesse contexto, a nova educação tem buscado a construção de um novo sujeito social, um novo tipo de trabalhador, que deverá ser multifuncional, polivalente, flexível e capaz de agir diante das diversas situações no âmbito do trabalho.

Como diz Noronha (2008, p. 28):

${ }^{6} \mathrm{O}$ advento da propriedade privada torna possível à classe dos proprietários viver do trabalho alheio, daqueles não proprietários que, por sua vez, passam a ter a obrigação de, com o seu trabalho, manterem-se a si e aos proprietários dos meios de produção. Estabelece-se, assim, uma cisão na unidade da educação, antes identificada plenamente com o próprio processo de trabalho; ela passa a ser constituída de duas modalidades distintas: uma para a classe proprietária, identificada como a educação dos homens livres, e outra para a classe não proprietária, identificada como a educação dos escravos e serviçais e trabalhadores livres. Ver Frigotto (2006), Saviani (2007) e Noronha (2008). 
As mudanças que estão ocorrendo no mundo do trabalho e das relações sociais, ao produzirem um "novo" tipo de trabalhador, o trabalhador coletivo combinado, passam a exigir, concomitantemente, um "novo" tipo de Educação, de Pedagogia e de formação de professores que sejam adequados à forma da cooperação complexa, para que haja condições de se formar um trabalhador que possa atender às novas demandas do mercado. Essas questões estão presentes nas reformas educacionais, com o objetivo de realizar a articulação de tais reformas das estruturas econômicas.

Como visto, no modelo de gestão taylorista/fordista, o trabalhador não era chamado a pensar sobre seu trabalho $\mathrm{O}$ princípio fundamental do taylorismo está na questão do tempo, tendo como pressuposto que os trabalhadores devem ser tratados como máquinas. O controle centraliza-se nas "mãos" da gerência, expressão máxima da separação entre o trabalho manual e o trabalho intelectual. Tanto que:

\begin{abstract}
Não é sempre necessário, para esse fim, que a máquina seja um modelo bem aperfeiçoado ou requintado de sua espécie. A esteira rolante, quando usada numa linha de montagem, embora seja primitivíssima parte da maquinaria, corresponde perfeitamente às necessidades do capital na organização do trabalho que não pode ser mecanizado de outro modo. Seu ritmo está nas mãos da gerência, e é determinado por um dispositivo mecânico cuja construção não poderia ser mais simples, mas que capacita a gerência a aproveitar-se do único e essencial elemento de controle do processo (BRAVERMAN, 1981, p. 169).
\end{abstract}

Portanto, Taylor desejava um "gorila adestrado", que soubesse executar as ordens da gerência científica (BRAVERMAN, 1981). Contrariamente, tem-se no capitalismo do século XXI, sob o toyotismo, a necessidade de formação de um trabalhador que deverá ser participativo, colaborador e inventivo. Estabelece-se, assim, uma conjugação de elementos subjetivos e comportamentais com formas flexíveis de emprego que se tornam fundamentais para assegurar o controle, a disciplina e o consentimento desse novo trabalhador no local de trabalho e também fora dele, uma vez que, a partir da nova configuração das bases materiais de produção estabelecem-se novas formas de relações sociais, culturais e educacionais (ANTUNES e ALVES, 2004; SEWELL, 1998; 2005).

Kuenzer (2003) ressalta que as características demandadas pelo mercado para a empregabilidade do novo trabalhador envolvem, além da capacidade de ser flexível, o desenvolvimento de competências cognitivas superiores e de relacionamento, tais como: análise, síntese, criatividade, rapidez de resposta, comunicação clara e precisa, interpretação e uso de diferentes formas de linguagem, capacidade para trabalhar em grupo e de liderar, gerenciar processos para atingir metas, trabalhar com prioridades, avaliar, lidar com as diferenças, enfrentar os desafios das mudanças permanentes e buscar aprender permanentemente.

A nova educação, bem como os novos processos pedagógicos, está orientada pelos conceitos de multifuncionalidade, flexibilidade e empregabilidade. Como alerta Noronha (2008), os novos tipos de educação e de processos pedagógicos não estão desvinculados das mudanças no processo de formação de professores e no próprio trabalho docente. Assim, ao mesmo tempo que uma nova pedagogia do trabalho é implementada, a formação e o trabalho docente vão sendo reestruturados, submetidos às novas formas de controle.

As estratégias de mudanças na formação e na atividade laboral docente que tiveram início nas reformas educacionais dos anos 1990 no Brasil implicaram a intensificação e desqualificação do trabalho e a precarização das relações laborais (OLIVEIRA, 2004; SILVA JÚNIOR, 2002; GARCIA e ANADON, 2009; MACIEL e PREVITALI, 2011).

No que tange à formação docente, Silva Júnior (2002) aponta que seu eixo central passa a ser o que e como ensinar, privilegiando as dimensões técnica e praticista do trabalho docente e proporcionando uma reprodução maciça de profissionais exclusivos para o mercado de trabalho. Para o autor, nesse processo, 
muitos professores perdem a identidade como classe trabalhadora, aderindo ao projeto político burguês e transmitindo conceitos como os de empreendedorismo, competitividade, inteligência emocional e polivalência. Outro recurso destacado pelo autor para que o professor não se sinta pertencente a uma categoria é a fragmentação das atividades docentes em diversas especialidades. Segundo Silva Júnior (2002), por meio da divisão das especialidades - administrador, supervisor, orientador, coordenador - o trabalhador docente não se identifica mais como professor e, trabalhando em diversas escolas, não se identifica nem com a escola em que trabalha nem com os problemas dela.

Acerca das relações laborais, Maciel e Previtali (2011) chamam a atenção para um processo de sujeição da subjetividade do trabalhador docente por meio dos mecanismos de controle que envolvem a busca de objetivação do seu saber por meio de procedimentos pré-estabelecidos em manais de ensino, apostilas e formulários de avaliação pela burocracia escolar e governamental, levando à desqualificação da prática pedagógica.

Segundo Garcia e Anadon (2009), entre os aspectos e as mudanças que apontam a precarização do trabalho dos professores podem-se destacar a ampliação das tarefas a ser desempenhadas no cotidiano das escolas, ao mesmo tempo que ocorre a desqualificação e intensificação da formação profissional pela pedagogia oficial das competências, pela padronização dos currículos do ensino básico e da formação docente, bem como pela instituição de exames nacionais que favoreceram a emergência de novas estratégias de controle, baseadas na auditoria, na vigilância e na supervisão direta dos professores pelos chamados especialistas da educação, implicando demanda intensa de trabalho burocrático para prestação de contas do ensino.

Para as autoras, a ótica neoliberal no contexto educacional estimula a "autorresponsabilização" (GARCIA e ANADON, 2009, p. 54) por parte dos professores, que, aliada à deterioração dos salários e das condições de trabalho, vem contribuindo para a intensificação e autointensificação do trabalho docente, afetando sobremaneira sua subjetividade.

Convém lembrar que Braverman (1981), ao analisar os trabalhadores da educação, argumenta que estes também estariam sujeitos a um processo de proletarização ${ }^{7}$, sendo seu trabalho, mediante a racionalização imposta pelo capital, caracterizado cada vez mais como manual do que como intelectual, havendo também, aqui, uma desqualificação do trabalho e um achatamento dos níveis salariais, levando, cada vez mais, à perda de seus valores, sejam eles simbólicos ou materiais. Assim, para Braverman (1981), a desqualificação do trabalho docente deve ser entendida como uma "perda na capacidade de realizar todas as etapas e tarefas da profissão docente, e pelas formas de descontrole sobre o coletivo docente instituídas com o tecnicismo" (BRAVERMAN, 1981, p. 235).

Para Braverman (1981), o termo qualificação sugere referir-se ao domínio de uma técnica aprendida após anos de treinamento. $\mathrm{O}$ autor cita o exemplo do cocheiro, que, além de ter habilidade com os animais, precisava entender de carroça, do manejo de ambos etc. Entretanto, ainda que o tempo necessário para se tornar um bom cocheiro fosse muito maior que o necessário para se tornar motorista, este é considerado mais qualificado.

Isso porque, como destaca Braverman (1981), a valorização da qualificação está sempre atrelada às necessidades momentâneas do mercado e não à apropriação de algum ofício e, mais ainda, não traz nenhuma garantia de emprego para o trabalhador. Para o autor, trabalho qualificado/complexo vale como trabalho superior ao desqualificado/simples, porque é a exteriorização da força de trabalho, na qual entram os custos mais altos de formação, cuja produção custa mais tempo de trabalho, e, por isso, tem valor mais elevado. Se o valor dessa força de trabalho é superior, ela se objetiva, nos mesmos períodos de tempo, em valores proporcionalmente mais altos.

${ }^{7}$ O termo proletarização faz referência à estrutura social cingida em classes sociais distintas. 
O autor esclarece:

O modo capitalista de produção destrói sistematicamente todas as perícias à sua volta, e dá nascimento a qualificações e ocupações que correspondem às suas necessidades. As capacidades técnicas são daí por diante distribuídas com base estritamente na "qualificação". A distribuição generalizada do conhecimento do processo produtivo entre todos os participantes torna-se desse ponto em diante, não meramente "desnecessária", mas uma barreira concreta ao funcionamento do modo capitalista de produção (BRAVERMAN, 1981, p. 79).

Sob a lógica da acumulação flexível, as reformas educacionais implementadas pelos governos neoliberais justificadas pelo discurso da empregabilidade devem ser entendidas como a necessidade do capital ter à disposição uma classe trabalhadora que possa, cada vez mais, produzir conhecimento para a produção de bens e serviços, devendo ser, ao mesmo tempo, criativa e adaptativa de modo a não questionar os processos socioideológicos do capital.

Portanto, a crítica que se faz à proposta de qualificação e requalificação tem em vista o uso ideológico desses termos, que tem por finalidade a redução do tempo de trabalho necessário e a expansão do mais trabalho, e, portanto, intensifica as condições de exploração da força de trabalho, como já afirmara Braverman (1981) há quarenta anos.

\section{Conclusão}

A realidade do trabalho contemporâneo resulta da forma que se desenvolve sob o capitalismo: a atividade humana é substituída pela máquina, "mas lança parte dos trabalhadores de volta a um trabalho bárbaro e faz da outra parte máquinas" (MARX, 2010, p. 82).

O que se observa a partir das últimas décadas do século XX e no início do século XXI é a construção de uma nova forma de racionalização do processo de trabalho que potencializa o controle e a vigilância no local de trabalho e impõe aos trabalhadores um intenso e cuidadoso monitoramento por meio das análises constantes de índices de produtividade, de desempenho, de satisfação, entre tantas outras, sob o domínio de uma estrutura administrativa fortemente hierarquizada.

As novas estruturas de controle são apresentadas sob a celebração da qualificação do trabalhador e de sua maior inserção intelectual no processo via recombinação entre trabalho mental e manual.

No entanto, como discutido ao longo deste artigo, a realidade do local de trabalho vem sendo marcada por mais intensificação, flexibilização e precarização das condições de trabalho, exigindo-se do trabalhador flexível submissão às jornadas de trabalho prolongadas, às horas extras sem pagamento, pois se tornam bancos de horas para ser tiradas em folga quando a empresa precisar reduzir a produção, multifuncionalidade para executar diferentes tarefas e operar vários tipos de máquinas e equipamentos, além de aptidões que favoreçam a iniciativa, a cooperação e o trabalho em grupos.

Essa estrutura de mando, associada a uma nova pedagogia da educação contribui fortemente para o desenvolvimento de um profundo senso de autocontrole, autodisciplina e autointensificação, implicando a degradação do trabalho. Assim como o trabalho manual, o trabalho intelectual também passa a sofrer um processo de desqualificação e precarização, implicando, no caso do trabalhador docente, uma autonomia na realização de seu trabalho, cada vez mais restringida.

Vale ressaltar que Braverman (1981), quando se refere à degradação do trabalho, defende a tese de que o capital promove não apenas a precarização das condições de trabalho, com aceleração de ritmos e imposição 
de movimentos repetitivos, mas, também, a reificação do trabalho alienado/estranhamento não apenas no local de trabalho, mas na estrutura social.

À medida que o número de trabalhadores se eleva e a oferta de empregos diminui, intensifica-se a concorrência entre eles, tornando-a tanto maior, mais inatural e mais violenta. Por outro lado, o capitalista beneficia-se dessa concorrência intratrabalho empregando os mais qualificados por menores salários e benefícios, contribuindo para perda do sentimento de classe dos trabalhadores e para o achatamento generalizado da sua renda (MARX, 2010).

A consequência mais evidente desse processo é a crescente de individualização do trabalhador, fragilizandoo socialmente e contribuindo para o enfraquecimento das ações sindicais, ao mesmo tempo que se torna fundamental a construção coletiva de novas práticas de resistência. Assim, as teses que defendem a perda do significado do trabalho na sociedade estão longe de ser confirmadas.

O grande desafio que se apresenta hoje, tanto na teoria quanto na prática, é entender a relação de produção especificamente capitalista e compreender como vem ocorrendo o processo de exploração nas relações produtivas, buscando desmistificar as concepções de reintegração entre trabalho mental e manual, de substituição do trabalho pela ciência e de mais qualificação.

\section{Referências}

AGLIETTA, M. A theory of capitalist regulation. London: Verso, 1979.

ANTUNES, R. Adeus ao trabalho? São Paulo: Cortez, 2000.

Os sentidos do trabalho. São Paulo: Boitempo, 2002.

. A classe trabalhadora hoje e a nova morfologia do trabalho: informalidade, infoproletariado, imaterialidade e valor. In: VARELA, R. (Coord.). A segurança social é sustentável. Lisboa: Bertrand, 2013. 337-362 p.

; ALVES, G. As mutações no mundo do trabalho na era da mundialização do capital. Educação \& Sociedade, v. 25, n. 87 , p. 335-351, 2004.

BIHR, A. Da grande noite à alternativa: o movimento operário europeu em crise. São Paulo: Boitempo, 1998.

BRAVERMAN, H. Trabalho e capital monopolista. Rio de Janeiro: Zahar, 1981.

BURAWOY, M. Toward a Marxist theory of the labour process: Braverman and beyond. Politics and Society, v. 8 , n. 3-4, p. 247-312, 1978.

CARTER, B. et al. They can't be the buffer any longer: front-line managers and class relations under white collar lean production. Capital \& Class, v. 38, n. 2, p. 323-343, 2014.

EDWARDS, R. Contested terrain: the transformation of the workplace in the twentieth century. London: Hinemann, 1979.

FRIGOTTO, G. Fundamentos científicos e técnicos da relação trabalho e educação no Brasil de hoje. In: LIMA, J. C. F.; NEVES, L. M. W. (Org.). Fundamentos da educação escolar do Brasil contemporâneo. Rio de Janeiro: Fiocruz, 2006. 233-263 p.

GARCIA, M. M. A; ANADON, S. B. Reforma educacional, intensificação e auto intensificação do trabalho docente. Educação \& Sociedade, v. 30, n. 106, p. 63-85, 2009. 
GOUNET, T. La stratégie japonaise de Iorissen. Études Marxistes, n. 37, 1997. Disponível em: <http://www.marx.be/fr/content/\%C3\%A9tudesmarxistes?action=get_doc\&id=33\&doc_id=193>. Acesso em: 10 jan. 2014.

HARVEY, D. Condição pós-moderna. São Paulo: Loyola, 1992.

O enigma do capital: as crises do capitalismo. São Paulo: Boitempo, 2011.

HOFFMAN, K.; KAPLINSK, R. Driving Force: the global restructuring of technology, labor and investment in the automobile and components industries. Boulder: Westview Press, 1988.

KUENZER, A. Z. Educação profissional: categorias para uma nova pedagogia do trabalho. Boletim Técnico do Senac, 2003. Disponível em: <http://www.senac.br/ BTS/252/boltec252b.htm>. Acesso em: 10 fev. 2011.

MACIEL, R. M.; PREVITALI, F. S. Impacto das políticas públicas do trabalhador da educação na rede estadual de ensino de Patos de Minas/MG em 2011. Revista Labor, v. 6, n. 1, p. 326-343, 2011.

MARX, K. O capital. São Paulo: Nova Cultural, 1988. v. 2.

Manuscritos econômicos e filosóficos de 1844. Trad. Jesus Ranieri. São Paulo: Boitempo, 2010.

MEIKSINS, P. Labor and monopoly capital for the 1990s: a review and critique of the labor process debate. 1994. Monthly Review, v. 46, n. 6, p. 45-59, 1994.

MILKMAN, R. Farewell to the factory: auto workers in the late twentieth century. Los Angeles, CA: University of California Press, 1997.

; LUCE, S. The state of the unions 2013: a profile of organized labor in New York City, New York State, and the United States. 2013. Disponível em: <https://sps.cuny.edu/filestore /8/6/3_bc 4b97196c5659e/863 _916e1989d05f0e6.pdf>. Acesso em: 12 dez. 2013.

NOGUEIRA, C. O trabalho duplicado: a divisão sexual do trabalho e na reprodução - um estudo das trabalhadoras do telemarketing. São Paulo: Expressão Popular, 2006.

NORONHA, O. M. Globalização, mundialização e educação. In: LUCENA, C. (Org.). Capitalismo, Estado, educação. Campinas, SP: Alínea, 2008. 23-35 p.

OLIVEIRA, D. A. A reestruturação do trabalho docente: precarização e flexibilização. Educação \& Sociedade, v. 25, n. 89 , p. 1127-1144, 2004.

PIORE, M.; SABEL, C. The second industrial divide: possibilities for prosperity. New York: Basic Books, 1984.

POLLERT. A. Team work on the assembly line: contradiction and the dynamics of union resilience, In: ACKERS, P. et al. (Eds.). The new workplace and trade unionism. London: Routledge, 1996, 124-143 p.

PREVITALI, F. S. O caso Mercedes-Benz: ABC e Campinas. In: ANTUNES, R. (Org.). Riqueza e miséria do trabalho no Brasil. São Paulo: Boitempo, 2006. 213-220 p.

. O controle do trabalho pelo discurso da qualificação do trabalhador no contexto da reestruturação produtiva do capital. Publicatio UEPG, v. 17, p. 141-155, 2009.

; FARIA, A. F. Reestruturação produtiva e novas formas de controle no local de trabalho: a experiência da indústria de fumo em Uberlândia-MG. Antíteses, v. 1, p. 1-25, 2008.

; MORAIS, S. P; FAGIANI, C. C. Ethanol workers in Brazil: the other side of wealth. Workers of the World, v. 1, n. 3, p. 227-245, 2013. 
SAVIANI, D. Trabalho e educação: fundamentos ontológicos e históricos. Revista Brasileira de Educação, v. 12, n. 34, p. 152-165, 2007.

SEWELL, G. The discipline of teams: the control of team-based industrial work through electronic and peer surveillance. Administrative Science Quarterly, v. 43, n. 2, p. 397-428, 1998. 2005.

Nice work? Rethinking managerial control in an era of knowledge. Organization, v. 12, n. 5, p. 685-704,

SILVA, M. A. M. Errantes do fim do século. São Paulo: Ed. Unesp, 1999.

SILVA JÚNIOR, J. R. Reforma do Estado e da educação no Brasil de FHC. São Paulo: Xamã, 2002.

THOMPSON. P. The capitalist labour process: concepts and connections. Capital \& Class, v. 34, n. 1, p. 7-14, 2010.

TOMANEY, J. A new paradigm of work organization and technology? In: AMIN, A. (Org.). Post-Fordism. Oxford: Blackwell, 1996. 24-52 p.

WOMACK, J.; JONES, D. T.; ROOS, D. The machine that changed the world. New York: Rawson Associates, 1989.

YATES, M. Braverman and the class struggle. Monthly Review, v. 50, n. 8, p. 2-11, 1999. Disponível em: <http://monthlyreview.org/1999/01/01/braverman-and-the-class-struggle>. Acesso em: 12 jan. 2014. 